\title{
Short-term mortality associated with failure to receive home care after hemiarthroplasty
}

\author{
Elham Rahme PhD, Susan R. Kahn MD MSc, Kaberi Dasgupta MD MSc, Mark Burman MD, \\ Sasha Bernatsky MD PhD, Youssef Habel BSc MPhil, Greg Berry MD
}

Previously published at www.cmaj.ca

\section{ABSTRACT}

Background: Hemiarthroplasty is often the treatment of choice after hip fracture, particularly in frail elderly patients. Such patients may benefit from home care after discharge. We assessed factors associated with the receipt of home care and evaluated the risk of death within three months after discharge.

Methods: We obtained administrative data for patients 65 years or older in the province of Quebec who were discharged alive from hospital after hemiarthroplasty during the period 1997-2004. We evaluated destination after discharge and mortality within three months after discharge.

Results: Of 11326 study patients, 5.6\% were discharged home with home care, $29.9 \%$ home without home care, $2.0 \%$ to a rehabilitation centre, $24.2 \%$ to a nursing home and $38.3 \%$ to another hospital. Among patients who were discharged home, those who were older, had osteoarthritis, had an emergent admission and were admitted to a high-volume hospital were less likely to receive home care. Discharge with home care was most likely among patients admitted to teaching hospitals, those in hospital for more than seven days, those with atrial fibrillation and those with acute renal failure. Patients who received home care were at lower risk of death than those discharged home without care (hazard ratio $0.57,95 \%$ confidence interval 0.39-0.85).

Interpretation: Less than $16 \%$ of the patients discharged home after hemiarthroplasty received home care. Those who received such care had a lower risk of death within three months after discharge.

$\mathrm{H}$ emiarthroplasty is often the treatment of choice after hip fracture, particularly among elderly people who have a displaced femoral neck fracture. ${ }^{1}$ These patients are typically frail and at high risk of complications and death. ${ }^{2-4}$ The risk of death among patients undergoing hemiarthroplasty is higher in the first three months after discharge $^{5}$ and is higher among men, older patients and those with comorbid conditions. ${ }^{5-7}$

Home care after orthopedic surgery has been shown to improve outcomes and reduce health care costs among patients receiving a hip replacement. ${ }^{8}$ In Quebec, home care after hospital discharge is provided by local community health centres (Centres locaux de services communautaires [CLSCs]). ${ }^{9}$ Patients scheduled for elective hip replacement participate in teaching programs before admission, and their destination after discharge is planned by their local health centre. ${ }^{10}$ For those discharged home, their local health centre provides nursing, physiotherapy, occupational therapy, nutrition and psychosocial care as well as daily housekeeping, depending on each patient's needs. ${ }^{10}$ Patients who undergo hemiarthroplasty to repair a hip fracture do not have the opportunity for such an evaluation by their local health centre. Despite their need for home care, the centre is unable to respond fully to their needs because of limited resources. ${ }^{11,12}$ Places in rehabilitation centres are also limited and are usually requested long before elective surgery. Therefore, many patients undergoing hip replacement are discharged home without rehabilitation or home care.

We assessed factors associated with the receipt of home care among elderly patients who underwent hemiarthroplasty. We evaluated the risk of death within three months after discharge.

\section{Methods}

\section{Study design and data sources}

We conducted a retrospective cohort study using provincial hospital discharge records as well as demographic and pharmacy claims data obtained from the Régie de l'Assurance Maladie du Québec. Coverage for hospital and physician services is provided free of charge to all Quebec permanent residents. Drug coverage is provided to all residents 65 years or older, those receiving social assistance and those younger than 65 years who do not have a collective drug insurance plan. ${ }^{13}$ The type of drug coverage is determined based on age and income. In general, for persons aged 65 years or older, three types of drug coverage exist: a guaranteed revenue sup-

From the Department of Medicine (Rahme, Kahn, Dasgupta, Bernatsky), McGill University; the Division of Clinical Epidemiology, Research Institute (Dasgupta, Bernatsky, Habel) and the Department of Surgery, Division of Orthopedic Surgery (Burman, Berry), McGill University Health Centre; and the Centre for Clinical Epidemiology and Community Studies (Kahn), Jewish General Hospital, Montréal, Que.

CMAJ 2010. DOI:10.1503/cmaj.091209 
plement plan, partial revenue supplement plan or no revenue supplement plan. Guaranteed revenue supplement indicates lower income. The demographic and hospital discharge summary databases have been described elsewhere. ${ }^{7,14}$ These databases are linkable through a unique patient identifier. Permissions from the Institutional Review Board of the Research Institute of the McGill University Health Centre and from the Government of Quebec Ethics Committee, the Commission d'Accès à l'Information, were obtained to use these data.

\section{Study population}

The province of Quebec has a population of about 7.5 million; at the time of our study, just over one million were aged 65 years or older. We included data for patients 65 years of age or older who underwent hemiarthroplasty in the province of Quebec between January 1997 and December 2004. We excluded patients who were admitted to hospital for one day only, because it was unlikely that hemiarthroplasty had occurred. We also excluded patients who died during their hospital stay.

We collected the following characteristics of patients assessed at the time of hospital discharge: demographic variables (age, sex, region of residence, high v. low income [as designated by the drug coverage plan for reimbursement purposes]); conditions related to the need for hemiarthroplasty (osteoarthritis, rheumatoid arthritis or hip fracture); presence of chronic diseases, determined from secondary diagnostic codes in the hospital discharge summary (cancer, ischemic heart disease, congestive heart failure, cerebrovascular disease, hypertension, diabetes mellitus and chronic renal failure); acute in-hospital diseases that may have been related to the surgery (deep vein thrombosis, gastrointestinal bleeding, hemorrhagic stroke and acute renal failure); hospital-related variables (length of hospital stay, type of hospital [teaching v. community] and hospital volume [total number of hemiarthroplasties performed during the study period]); and destination after discharge (home without care, home with care, rehabilitation centre, nursing home or another hospital). "Home without care" referred to patients who were discharged home without home care services provided by their local health centre; "home with care" referred to patients discharged home with such care.

\section{Main outcome measures}

The main outcomes evaluated were destination after discharge (home without care, home with care, rehabilitation centre, nursing home or another hospital) and mortality within the first three months after discharge.

\section{Statistical analysis}

We report patient characteristics and outcome variables using means and standard deviations, or proportions, as appropriate. We investigated the linearity of the logit of discharge destination and of the log-hazard of mortality with respect to the continuous variables using residual-based plots. ${ }^{15}$ Because of a strong departure from linearity, hospital volume was categorized based on the median and upper quartile of the number of hemiarthroplasties performed during the study period. We used polytomous logistic regression models to identify determinants of discharge destination. All patient and hospital characteristics listed earlier that were significant at a level of $p \leq 0.25$ were included in the model. ${ }^{16}$ A backward selection was used whereby a variable that was not significant at a level of $p=0.10$ was removed from the model..$^{16}$ Multicolinearity was assessed using the variance inflation factor. A variance inflation factor of 10 or greater is an indication of multicolinearity. ${ }^{17}$

Kaplan-Meier curves were plotted to show unadjusted time to death during the three-month period after discharge by discharge destination. We used Cox proportional hazard models to examine the association between discharge destination and time to death within the first three months after discharge after we adjusted for patient and hospital characteristics. We included the destination after discharge in all models because it was our main variable of interest. All patient and hospital characteristics listed earlier that were significant at a level of $p \leq 0.25$ were also included in the models. A backward selection was used whereby we removed from the model variables that were not significant at a level of $p=0.10$ and those whose removal from the model did not alter the estimate of the variable of interest (i.e., discharge destination) by more than 5\%. Interactions between destination on discharge and patient and hospital characteristics were also investigated. Interaction terms that were significant at the level of $p \leq 0.05$ were kept in the model. The proportional hazard assumption was checked by examining the plots of $\log (-\log$ [survival]) versus $\log$ of survival time in the five destination groups.

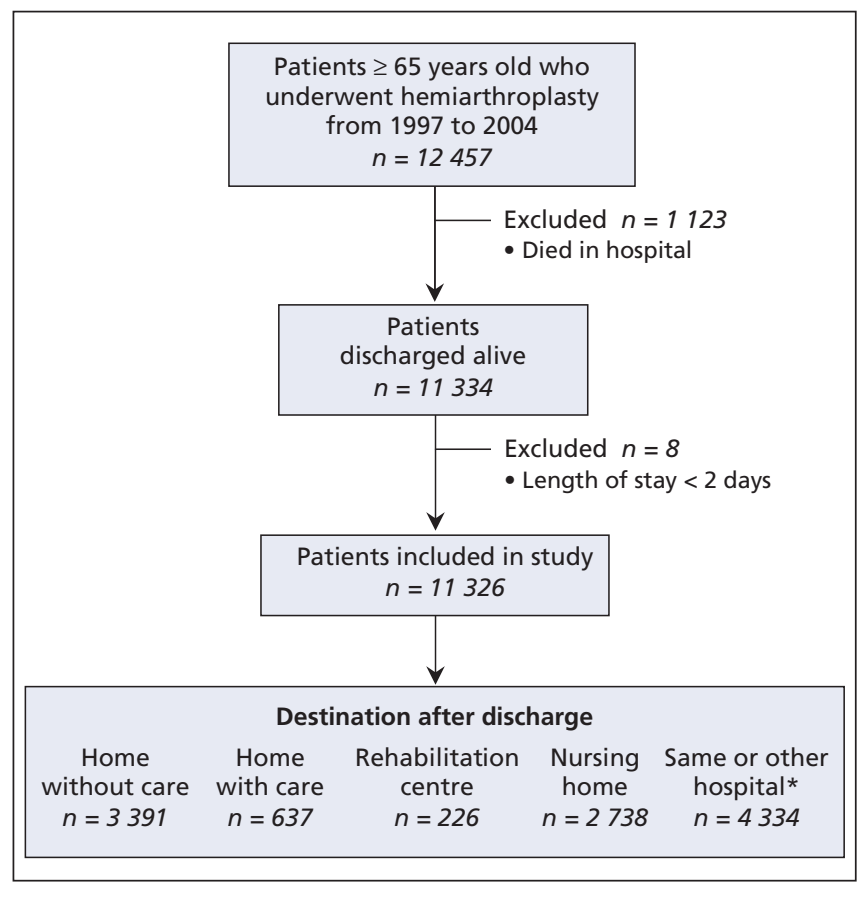

Figure 1: Selection of patients for the study cohort. *Includes patients transferred to another hospital and patients readmitted to hospital on the same day as discharge. 
Use of anticoagulant medication after discharge was found to be beneficial in reducing risk of all-cause mortality in another study conducted by our group. ${ }^{7}$ Data on anticoagulant use after discharge in the current study were available only for patients discharged home. Therefore, we conducted subgroup analyses in which we included only patients who were discharged home (with or without home care) and examined the effect on the results of adjusting for anticoagulant use after discharge.

\section{Results}

\section{Patient characteristics}

We identified 12457 patients aged 65 or older who had a pro-

Table 1: Characteristics of patients at discharge, by destination after discharge $(n=11326)$

\begin{tabular}{|c|c|c|c|c|c|c|c|c|c|c|}
\hline \multirow{2}{*}{$\begin{array}{l}\text { Characteristic } \\
\text { Age, yr, mean (SD) }\end{array}$} & \multicolumn{10}{|c|}{ Destination after discharge; no. (\%) of patients* } \\
\hline & 81.3 & $(7.5)$ & 79.3 & $(7.3)$ & 80.8 & $(7.2)$ & 83.3 & $(7.1)$ & 81.2 & $(7.2)$ \\
\hline Sex, male & 708 & $(20.9)$ & 161 & $(25.3)$ & 52 & $(23.0)$ & 606 & $(22.1)$ & 968 & $(22.3)$ \\
\hline Home & 3218 & $(94.9)$ & 627 & $(98.4)$ & 213 & $(94.3)$ & 1798 & $(65.7)$ & 3815 & $(88.0)$ \\
\hline Other & 124 & $(3.7)$ & 8 & $(1.3)$ & & $(3.5)$ & 54 & $(2.0)$ & 474 & (10.9) \\
\hline Region of residence, rural & 712 & $(21.0)$ & 148 & $(23.2)$ & & $(25.7)$ & 431 & $(15.7)$ & 593 & $(13.7)$ \\
\hline Higher income $\neq$ & 1129 & $(33.3)$ & 231 & $(36.3)$ & & $(29.2)$ & 676 & $(24.7)$ & 1829 & $(42.2)$ \\
\hline Osteoarthritis & 407 & $(12.0)$ & 71 & $(11.2)$ & 24 & $(10.6)$ & 232 & $(8.5)$ & 450 & $(10.4)$ \\
\hline \multicolumn{11}{|l|}{ Acute in-hospital complication } \\
\hline Deep vein thrombosis & 57 & $(1.7)$ & 10 & $(1.6)$ & 2 & $(0.9)$ & 48 & $(1.8)$ & 72 & $(1.7)$ \\
\hline Gastrointestinal bleeding & 21 & $(0.6)$ & 4 & $(0.6)$ & 0 & & 13 & $(0.5)$ & 23 & $(0.5)$ \\
\hline Hemorrhagic stroke & 1 & $(0.0)$ & 0 & & 0 & & 4 & $(0.1)$ & 3 & $(0.1)$ \\
\hline Acute renal failure & 23 & $(0.7)$ & 13 & $(2.0)$ & 4 & $(1.8)$ & 37 & $(1.3)$ & 42 & $(1.0)$ \\
\hline \multicolumn{11}{|l|}{ Chronic diseases } \\
\hline Cerebrovascular disease & 269 & (7.9) & 52 & $(8.2)$ & 18 & $(8.0)$ & 313 & $(11.4)$ & 339 & (7.8) \\
\hline Cancer & 186 & $(5.5)$ & 44 & $(6.9)$ & 12 & $(5.3)$ & 130 & $(4.7)$ & 221 & (5.1) \\
\hline Teaching hospital & 1244 & $(36.7)$ & 260 & $(40.8)$ & 51 & $(22.6)$ & 1153 & $(42.1)$ & 2213 & $(51.1)$ \\
\hline Emergent admission & 3153 & $(93.0)$ & 560 & $(87.9)$ & 212 & $(93.8)$ & 2683 & $(98.0)$ & 4108 & $(94.8)$ \\
\hline Hospital volume, mean (SD) & 279.8 & (157.3) & 258.3 & (116.3) & 226.4 & $(70.5)$ & 286.0 & (140.2) & 342.5 & (146.6) \\
\hline \multicolumn{11}{|l|}{ Length of hospital stay, $d$} \\
\hline $2-7$ & 568 & $(16.8)$ & 52 & $(8.2)$ & 18 & $(8.0)$ & 696 & $(25.4)$ & 1281 & $(29.5)$ \\
\hline $8-14$ & 1185 & (34.9) & 213 & (33.4) & & $(42.5)$ & 757 & $(27.6)$ & 1733 & $(40.0)$ \\
\hline $15-29$ & 903 & $(26.6)$ & 218 & $(34.2)$ & & (31.4) & 592 & $(21.6)$ & 1047 & $(24.2)$ \\
\hline$\geq 30$ & 735 & $(21.7)$ & 154 & $(24.2)$ & & $(18.1)$ & 693 & $(25.3)$ & 273 & (6.3) \\
\hline
\end{tabular}

Note: $\mathrm{SD}=$ standard deviation.

*Unless stated otherwise.

tIncludes patients transferred to another hospital and patients readmitted to hospital on the same day as discharge.

$\neq$ Compared with patients receiving any guaranteed revenue supplement as defined by the drug reimbursement plan. 
cedure code for hemiarthroplasty during the study period. We excluded 1123 who died in hospital and 8 who were in hospital for only one day. Of the 11326 patients whose data were included in the study, $9569(84.5 \%)$ were admitted from home, $10144(89.6 \%)$ were admitted for treatment of a hip fracture, and $10761(95.0 \%)$ had emergent admissions. The destination after discharge was home without care for 3391 patients $(29.9 \%)$, home with care for $637(5.6 \%)$, a rehabilitation centre for 226 (2.0\%), a nursing home for 2738 (24.2\%) and another hospital for 4003 (35.3\%) (Figure 1); 331 patients $(2.9 \%)$ were readmitted to hospital on the same day as discharge. In total, $84.2 \%$ of the 4028 patients discharged home did not receive home care. Of the 4003 patients transferred to another hospital, $2848(71.1 \%)$ were admitted to an orthopedic unit, $594(14.8 \%)$ to medicine, $242(6.0 \%)$ to geriatrics, $206(5.1 \%)$ to a rehabilitation unit and $113(2.8 \%)$ to other units.

\section{Factors associated with discharge home without care}

Patients' characteristics at discharge are shown by destination in Table 1. Compared with patients discharged home without care, those discharged home with care were younger (odds ratio [OR] per one-year increase $0.97,95 \%$ confidence interval [CI] 0.95 0.98), less likely to have osteoarthritis (OR 0.66, 95\% CI 0.490.90), less likely to have been admitted to a high-volume hospital (OR 0.98 , 95\% CI $0.98-0.99$, for every 10 additional hemiarthroplasties) and less likely to have had an emergent admission (OR $0.57,95 \%$ CI 0.38-0.85). They were more likely to have been admitted to a teaching hospital (OR 1.52, 95\% CI 1.24-1.86), to have stayed more than 7 days in hospital (8-14 days: OR 1.78, 95\% CI 1.29-2.46; 15-30 days: OR 2.42, 95\%

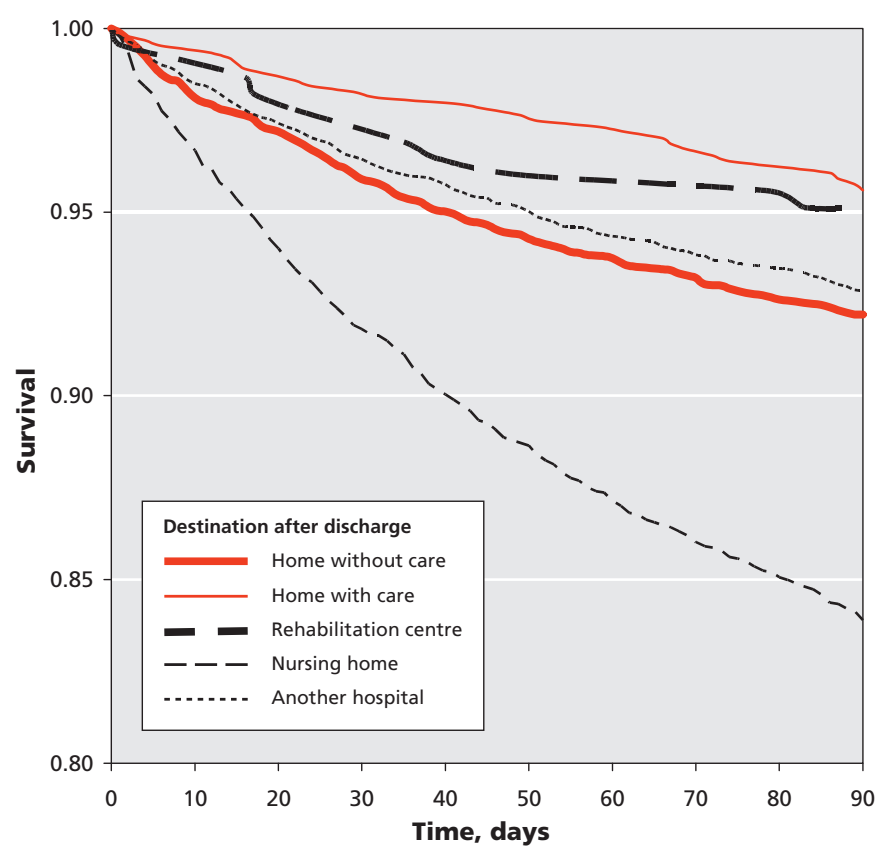

Figure 2: Kaplan-Meier curves depicting survival by destination after discharge among patients 65 years of age and older who underwent hemiarthroplasty
CI 1.75-3.35; > 30 days: OR 2.22, 95\% CI 1.58-3.12), to have atrial fibrillation (OR 1.99, 95\% CI 1.33-2.97) and to have acute renal failure (OR 2.88, 95\% CI 1.43-5.81).

\section{Mortality after discharge}

Kaplan-Meier curves depicting time to death by discharge destination are shown in Figure 2. The rate of death per 100 patient-months was lowest among patients discharged home with care (Table 2). The lower likelihood of death among those receiving home care after discharge compared to those discharged home without home care was confirmed in a multivariable Cox-proportional hazard model (Table 3). The risk of death within three months after discharge increased with age and was higher among men, those admitted from a nursing home, those who had acute gastrointestinal bleeding or acute renal failure in hospital, those with certain comorbid conditions (cancer, ischemic heart disease, heart failure, diabetes, atrial fibrillation) and those with an emergent admission (Table 3). Patients with higher income and those whose hospital stay was more than 7 days were at lower risk of death (8-14 days: OR $0.73,95 \%$ CI $0.62-0.86 ; 15-30$ days: OR $0.67,95 \%$ CI $0.56-0.81$; > 30 days: OR $0.74,95 \%$ CI $0.61-$ 0.90) (Table 3).

\section{Subgroup analyses}

When we included only patients discharged home (with or without care) in the Cox regression models and adjusted for anticoagulant use at discharge, the results were similar to those of the main model. The risk of death among those with home care was lower than the risk among those without home care (adjusted hazard ratio [HR] 0.67, 95\% CI 0.45-1.00). Use of anticoagulants after discharge also reduced the risk of death (HR 0.47, 95\% CI 0.32-0.70); however, the removal of this variable from the model did not alter the results of home care (HR 0.64, 0.43-0.95), which indicated that anticoagulant use did not confound the results of the main model.

\section{Interpretation}

Our study revealed that more than $84 \%$ of elderly patients discharged home after hemiarthroplasty did not receive home care after discharge. Patients who received home care were at $43 \%$ lower risk of death within the first three months after discharge than those discharged home without such care.

Comorbid conditions, with the exception of atrial fibrilla-

Table 2: Crude rates of death per 100 patient-months during the first three months after discharge

\begin{tabular}{lrcc}
\hline Destination & $\begin{array}{c}\text { Follow-up, } \\
\text { months }\end{array}$ & $\begin{array}{c}\text { No. of } \\
\text { deaths }\end{array}$ & $\begin{array}{c}\text { Rate of death per } \\
\text { 100 patient-months }\end{array}$ \\
\hline Home without care & 9682 & 264 & 2.7 \\
$\begin{array}{l}\text { Home with care } \\
\begin{array}{l}\text { Rehabilitation } \\
\text { centre }\end{array}\end{array}$ & 1870 & 28 & 1.5 \\
Nursing home & 7411 & 441 & 1.7 \\
Another hospital & 12446 & 309 & 6.0 \\
\hline
\end{tabular}


tion and acute renal failure, did not seem to influence the likelihood of receiving home care after discharge. This finding suggests that receiving home care may depend mostly on availability rather than on need for the service. Shortage of services provided by local community health centres in Quebec is well known, and allocation of this limited resource may not be prioritized to those of highest need. ${ }^{11} \mathrm{~A}$ report published by the Canadian Institute for Health Information revealed that Quebec is the province that spends the least on home care and has the highest number of demands for such care. ${ }^{18}$ In addition, most complaints received by consumer protection from Quebec residents concerning service provided by their local community health centres are about poor or inadequate home service. ${ }^{12}$

In our study, younger patients, patients admitted to teaching hospitals, those admitted to lower-volume hospitals and patients in hospital for more than seven days were more likely to receive home care after discharge. Availability of home care may explain the association between teaching and lower-volume hospitals and the receipt of the service. The positive association between home care after discharge and longer hospital stay, together with its lack of association with most comorbidity factors, may indicate that some patients remained in hospital until services provided by their local community health centre, a rehabilitation centre or a nursing home became available to them. This scenario, if true, implies a considerable waste of resources, with patients unnecessarily occupying much-needed hospital beds because of lack of availability of alternative services. This finding deserves further investigation.

Higher mortality among patients receiving hemiarthroplasty for hip fracture than among patients receiving elective arthroplasty has been observed by other authors, ${ }^{6}$ but no other study has evaluated the impact of receiving home care on survival in the first three months after discharge. As in other studies, men in our study were at higher risk of death than were women, ${ }^{5,19-21}$ and length of hospital stay was positively associated with increased likelihood of survival. ${ }^{21-23}$ Premature discharge is a possible explanation for the association between length of hospital stay and survival.
Table 3: Factors associated with patient death within three months after discharge $(n=11326)$

\begin{tabular}{lll}
\hline Factor & $\begin{array}{c}\text { Unadjusted HR } \\
(95 \% \mathrm{Cl})\end{array}$ & $\begin{array}{c}\text { Adjusted HR* } \\
(95 \% \mathrm{Cl})\end{array}$ \\
\hline $\begin{array}{l}\text { Destination after discharge (v. home } \\
\text { without care) }\end{array}$ & & \\
\hline \multicolumn{1}{l}{ Home with care } & $0.55(0.37-0.81)$ & $0.57(0.39-0.85)$ \\
\hline Rehabilitation centre & $0.62(0.34-1.12)$ & $0.55(0.30-1.00)$ \\
\hline Nursing home & $2.16(1.86-2.25)$ & $1.58(1.34-1.88)$ \\
\hline Another hospital & $0.91(0.77-1.07)$ & $0.83(0.70-0.98)$ \\
\hline Age, per 1-year increase & $1.06(1.05-1.07)$ & $1.05(1.04-1.06)$ \\
\hline Sex, male (v. female) & $1.76(1.54-2.00)$ & $1.72(1.50-1.97)$ \\
\hline Residence at admission (v. home) & & $1.60(1.32-1.93)$ \\
\hline $\begin{array}{l}\text { Nursing home } \\
\text { Other }\end{array}$ & $2.80(2.40-3.27)$ & $1.90(1.51-2.40)$ \\
\hline Region of residence, rural (v. urban) & $1.75(1.40-2.18)$ & - \\
\hline Higher income (v. receipt of any & $0.72(0.63-0.83)$ & $0.86(0.75-0.99)$ \\
\hline guaranteed income supplement) & & \\
\hline
\end{tabular}

$1.45(1.15-1.82)$

$0.77(0.48-1.25)$

$0.73(0.58-0.91)$

Osteoarthritis

Acute in-hospital complication (v.

absence of complication specified)

Deep vein thrombosis

$1.33(0.88-2.02)$

Gastrointestinal bleeding

$2.69(0.59-4.56)$

Hemorrhagic stroke

$1.45(0.20-10.25)$

Acute renal failure

$2.72(1.86-3.99)$

$2.79(1.64-4.75)$

$1.86(1.26-2.74)$

Chronic disease (v. absence of disease specified)

Cerebrovascular disease

1.38 (1.14-1.66)

1.19 (0.98-1.44)

Cancer

$3.41(2.88-4.04)$

$3.57(3.00-4.25)$

Ischemic heart disease

$1.50(1.31-1.70)$

$1.29(1.13-1.48)$

Chronic renal failure

$1.81(1.42-2.30)$

Heart failure

$1.89(1.60-2.22)$

$1.43(1.21-1.70)$

Hypertension

Diabetes mellitus

$0.79(0.70-0.90)$

$0.83(0.73-0.95)$

$1.30(1.10-1.52)$

$1.27(1.08-1.49)$

Atrial fibrilation

$2.39(1.89-3.03)$

$2.20(1.72-2.80)$

Hospital-related variable

Teaching hospital

$0.90(0.79-1.01)$

Emergent admission

$3.82(2.33-6.27)$

$2.24(1.36-3.68)$

Hospital volume, per 10 additional hemiarthroplasties

Length of hospital stay, $d$ (v. 2-7 days)

$8-14$
$15-29$
$\geq 30$

8-14

$0.63(0.54-0.74)$

$0.73(0.62-0.86)$

$0.64(0.54-0.77)$

$0.67(0.56-0.81)$

$0.93(0.78-1.11)$
Note: $\mathrm{Cl}=$ confidence interval, $\mathrm{HR}=$ hazard ratio.

*All listed variables were entered into the original model. Variables that were not significant at the 0.1 level and whose removal did not alter the effect of destination after discharge by more than $5 \%$ were removed in a backward selection. 


\section{Strengths and limitations}

Strengths of our study include our use of large, populationbased administrative databases, which contained data collected independently of the study objectives. The databases included a large number, but not all, of the relevant variables for the study questions. The databases and study design afforded us the opportunity to examine rates of death. associated with destination after discharge in the clinical practice setting.

Limitations of our study also pertain to the use of administrative databases; patient frailty is difficult to assess, and the reasons driving the choice of discharge destination are unknown. Although we adjusted our analyses for known patient characteristics, information on some potential confounders was not available in the database. For example, we were unable to adjust for receipt of social support or living alone, for severity of medical conditions and for patients' functional status. However, in theory, patients who have more severe conditions and who live alone should be more likely to receive home care. Therefore, adjusting for these confounders would likely strengthen the result toward a stronger effect. Some hospitals have a rehabilitation unit, indicated in the data by a code (i.e., "service $=45$ "). Using this code, we found that 560 patients $(4.9 \%)$ used the rehabilitation unit of the hospital. Of these patients, $123(22.0 \%)$ were discharged home without care, 27 (4.8\%) were discharged home with care, $26(4.6 \%)$ were discharged to a rehabilitation centre, 90 (16.1\%) were discharged to a nursing home, and 294 (52.5\%) were transferred to another hospital. Patients who use a hospital's rehabilitation unit and are discharged home may still require home care after discharge. Therefore, these patients were included in the analyses.

\section{Conclusion}

Our study revealed that home care for patients discharged after hemiarthroplasty may be suboptimal in the province of Quebec. Most patients discharged home did not receive home care in the first three months after discharge, potentially resulting in preventable deaths. This finding has important public health implications and requires further investigation.

\section{This article has been peer reviewed.}

\section{Competing interests: None declared.}

Contributors: All of the authors had full access to the data and participated in the design and conduct of the study and in the analysis and interpretation of the data. All of the authors participated in the writing of the manuscript and approved the final version submitted for publication.

Funding: This study was supported by a grant from the Canadian Institutes of Health Research (grant no. MOP-77815). Elham Rahme is a Senior Investigator of the Fonds de recherche en santé du Québec (FRSQ). Susan Kahn is a National Investigator (chercheur national) of the FRSQ. Kaberi Dasgupta and Sasha Bernatsky are physician-scientists funded by the Canadian Institutes of Health Research.

\section{REFERENCES}

1. Ahn J, Man LX, Park S, et al. Systematic review of cemented and uncemented hemiarthroplasty outcomes for femoral neck fractures. Clin Orthop Relat Res 2008;466:2513-8.

2. de Luise C, Brimacombe M, Pedersen L, et al. Comorbidity and mortality following hip fracture: a population-based cohort study. Aging Clin Exp Res 2008;20: 412-8.

3. Radcliff TA, Henderson WG, Stoner TJ, et al. Patient risk factors, operative care, and outcomes among older community-dwelling male veterans with hip fracture. J Bone Joint Surg Am 2008;90:34-42.

4. Jiang HX, Majumdar SR, Dick DA, et al. Development and initial validation of a risk score for predicting in-hospital and 1-year mortality in patients with hip fractures. J Bone Miner Res 2005;20:494-500.

5. Cree M, Yang Q, Scharfenberger A, et al. Variations in treatment of femoral neck fractures in Alberta. Can J Surg 2002;45:248-54.

6. Parvizi J, Ereth MH, Lewallen DG. Thirty-day mortality following hip arthroplasty for acute fracture. J Bone Joint Surg Am 2004;86-A:1983-8.

7. Rahme E, Dasgupta K, Burman M, et al. Postdischarge thromboprophylaxis and mortality risk after hip- or knee-replacement surgery. CMAJ 2008;178:1545-54.

8. Mahomed NN, Davis AM, Hawker G, et al. Inpatient compared with home-based rehabilitation following primary unilateral total hip or knee replacement: a randomized controlled trial. J Bone Joint Surg Am 2008;90:1673-80.

9. Programs and services for seniors. Montréal (QC): Services Quebec; 2009. Available: www.55ans.info.gouv.qc.ca/en/publications/Guide_Aînés_ang_final.pdf (accessed 2010 June 25).

10. Cadre de référence. Arthroplastie totale de la hanche et du genou CHSGS-CLSCCHR-médecins. Montréal (QC): Agence de développement de réseaux locaux de services de santé et de services sociaux de Montréal; 2009. Available: www.santemontreal.qc.ca/pdf/documentations/pubs/cadreref-arthroplastie200505.pdf (accessed 2010 June 25).

11. L'allocation des ressources et la budgétisation des services de CLSC et de CHSLD. Québec (QC): Santé et Services sociaux du Quebec; 2010. Available: http:// publications.msss.gouv.qc.ca/acrobat/f/documentation/2002/02-604-02.pdf (accessed 2010 June 25).

12. Les centres locaux de services communautaires. Québec (QC): Le Protecteur du citoyen; 2010. Available: www.protecteurducitoyen.qc.ca/fileadmin/medias/pdf /rapports_annuels/2006-07/RA_0607_27.pdf (accessed 2010 June 25).

13. L'assurance médicaments, c'est obligatoire. Québec (QC): Régie de l'assurance maladie Quebec; 2010. Available: www.ramq.gouv.qc.ca/fr/citoyens/assurancemedicaments/index.shtml (accessed 2010 June 25).

14. Contenu des banques. Québec (QC): Régie de l'assurance maladie Quebec; 2010. Available: www.ramq.gouv.qc.ca/fr/statistiques/banques/contenudesbanques.shtml (accessed 2010 June 25).

15. Hosmer D, Lemeshow S. Applied survival analysis: regression modeling of time to event data. New York (NY): Wiley; 1999.

16. Hosmer DW, Lemeshow S. Applied logistic regression. 2nd ed. Toronto (ON): John Wiley \& Sons; 2000.

17. Weisberg S. Applied linear regression. Wiley series in prohability and statistics. 3rd ed. John Wiley \& Sons; 2005.

18. Public-sector expenditures and utilization of home care services in Canada: exploring the data. Ottawa (ON): Canadian Institute for Health Information; 2007. Available: http://secure.cihi.ca/cihiweb/products/trends_home_care_mar_2007_e .pdf (accessed 2010 June 25).

19. Bass E, French DD, Bradham DD, et al. Risk-adjusted mortality rates of elderly veterans with hip fractures. Ann Epidemiol 2007;17:514-9.

20. Healy WL, Iorio R. Total hip arthroplasty: optimal treatment for displaced femoral neck fractures in elderly patients. Clin Orthop Relat Res 2004;429:43-8.

21. Shah SN, Wainess RM, Karunakar MA. Hemiarthroplasty for femoral neck fracture in the elderly surgeon and hospital volume-related outcomes. $J$ Arthroplasty 2005;20:503-8.

22. Petersen MB, Jorgensen HL, Hansen K, et al. Factors affecting postoperative mortality of patients with displaced femoral neck fracture. Injury 2006;37:705-11.

23. Lavernia CJ. Hemiarthroplasty in hip fracture care: effects of surgical volume on short-term outcome. J Arthroplasty 1998;13:774-8.

Correspondence to: Dr. Elham Rahme, Division of Clinical

Epidemiology, McGill University Health Centre, 687 Pine Ave. W, Montréal QC H3A 1A1; elham.rahme@mcgill.ca 